\title{
Features of application of fundamental knowledge in innovative space: ontological aspect
}

Julia Kharchenko*, Sergej Kharchenko, Olena Sidorkina, Alla Fabrika, and Oleg Rusul

National Aviation University, 1 Kosmonavta Komarova ave, 1, Kyiv, 03058, Ukraine

\begin{abstract}
The analysis of the innovative space with a complex structure and configuration has been conducted by showing that its space-time frame is uncertain due to the high dynamics. The results obtained from the analysis of virtuum as a kind of multidimensional reality, forming a new image of society and, at the same time, generating and combining new knowledge. Knowledge and innovation are shown as the fundamental dominant of the current model of society and as the result this model combines the characteristics of informational, cybercultural, technogenic, virtual, and innovative society. On this basis, the main purpose of the research was implementation of the correlation of innovative creations and new epistemes, which were the foundation of the innovative space. The ontological approach that became the theoretical basis of this research showed that the innovative space is understood as one of the multidimensional sphere of social existence as such, including all actors of innovation. The results of the research confirmed that fundamental knowledge is updating the epistemological resource, at the same time, the mechanisms and methodology of research are constantly changing, technical and technological tools are being modernized and all of these factors influence on innovative space. Besides, innovative space as an artificial environment is correcting social and natural phenomena.
\end{abstract}

\section{Introduction}

Innovative space is a relatively new sphere of social existence, which, however, binds together all other areas that exist in it - social, economic, scientific, educational, cultural, managerial, industrial, intellectual, virtual, spiritual, as well as sphere of business and communications, and others. It should be noted that the global world is becoming more technologically connected, interdependent, and its strategies, tactics, rules and requirements are constantly changing. Therefore, the field of innovation is presented as a systemic form of organization of all these areas, presented as objects of innovation. It creates not only an individual model of socio-economic relations, but also defines the commercial interests of global players on economic, political, cultural and other platforms.

\footnotetext{
*Corresponding author: kharchenkojv@gmail.com
} 
In the broad ontological sense of the word, the key goal of innovation is the innovative transformation of the current and changing reality, the complete modernization of the holistic architecture of everyday life. In the narrow utilitarian-consumer sense of the word, innovation is aimed at the production and sale of new ideas.

The innovative space has a complex structure and configuration, but its space-time frame is uncertain due to the high dynamics. At the same time, it is presented as a kind of virtuum - multidimensional and multi-level formation, forming a new image of society and, at the same time, generating and combining new knowledge. In today's society a so-called "new effect" acts because there is a search for qualitatively new ideas and solutions, and there is a conflict between old and new ideologies, generations, and images of thought.

Knowledge and innovation become the fundamental dominants of life in the model of society that is being formed at the moment. This model combines the characteristics of a new type of society - informational, cybercultural, technogenic, virtual, and innovative. On this basis, it is necessary to correlate innovative creations and new epistemes, which are the foundation of the innovative space.

The problem of transforming society into a virtuum of cultures, logics, mentalities, and images of thought by assessing the role of fundamental knowledge in combining the ethical factors is also actualized.

\section{Materials and methods}

In the context of the ontological approach, the innovative space can be understood as one of the many dimensions of existence or social existence as such, including all subjects of innovation. Its content is revealed in such categories as "something new" and "no new", "possible new" and "impossible new", "certain perspective" and "uncertain perspective", "quantity of knowledge" and "measure of application of new", "quality of knowledge", "the application of knowledge" and "knowledge as truth", as well as in the concepts of "space of innovation", "time for innovation", "movement of innovation processes", "knowledge as a form of life", "becoming a new idea", "the origin of a new idea", "transition from the old to new".

Ontological analysis of the phenomenon of fundamental knowledge, which influences innovative processes, is aimed at revealing the objective status of the ideal objects and theoretical constructs that they create. The ontological approach facilitates the modeling of the conceptual scheme of society as a virtuum, which consists of a structure containing a set of planes forming this virtuum (see figure 1 below).

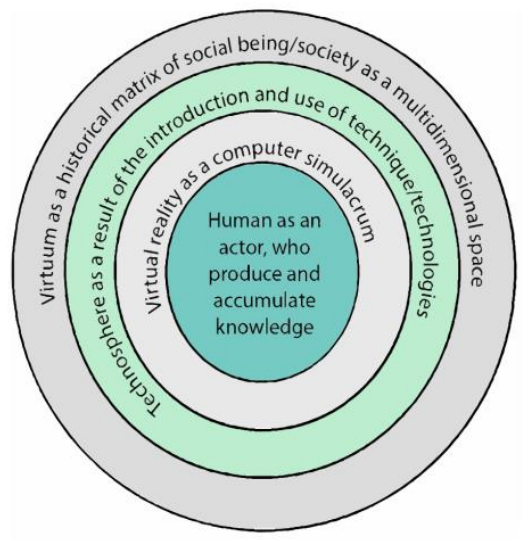

Fig. 1. Society as a virtuum, creating an innovative space 
Result: Innovation is a transformative factor that transforms an entire society.

The ontological approach is also applied as a fundamental philosophical methodological principle that encompasses "knowledge" in the broadest sense of the word as an object "as such". In this context, innovation serves as a projection of innovative reality, and the innovative space looks like system-structural integrity. Other components of the social virtuum are objectified and interpreted in the new ontological architecture of the innovative space.

The diversity of forms of social virtuum ontologically is due to the variety of innovations that continuously change the segments of the social matrix. Therefore, the ontological approach is designed to understand the essence of innovative processes, to study the emergence of innovations and technologies, to understand the structure of the innovation space, to analyze social existence as a complex system.

\section{Results}

The word "innovation" (in Latin "novatio" - "update," "change"; "in" - "in the direction"; "innovatio" - "in the direction of change") is not new. It was first mentioned in scientific research of the XIX century. At the beginning of the XX century, J. Schumpeter defined innovation as a new combination of production factors developed by the spirit of entrepreneurship [1]. As a result of the analysis of "innovative combinations" changes are being implemented in the development of local economic systems. A high-quality economic system determines the level of development of the global economy as a whole, changes the image of the economy as a sphere of social existence.

Today, the "market" penetrates into the sphere of knowledge, fundamentally changing its true spiritual purpose. Knowledge is no longer perceived as a sacrament in the philosophical meaning of the word, but as capital. The theory of "market defects" shows the contradictory nature of the "knowledge market" [2]. That is, knowledge is not identified with meanings, creative idea, but with the possibilities of their application and transformation in order to gain benefit. There is, therefore, a contradiction in understanding the essence of innovation, which is outlined in the approaches of philosophers and marketers.

Innovation as such seriously improves the efficiency of the current system. For example, innovation today is associated with the production of high-quality new products, services, offers, the creation of new markets and the introduction to these markets of new type of products with modernized consumer properties, the maximum increase efficiency of production systems and production processes.

The innovative space summarizes innovation and intensifies the intellectual work of the scientific community, establishes a dialogue between various scientific organizations and schools, enriches the creative process, promotes to expand the horizons of consciousness and imagination, as well as to the realization of discoveries and inventions.

Innovation is the result of the application of fundamental research, which has historically been aimed at finding the fundamental laws of nature. They significantly expand fundamental knowledge about the world and man; contribute to the emergence of new theories explaining not only natural phenomena, but also the essence of social and spiritual processes. Fundamental research is a generator of deep scientific ideas, which, materializing and embodying, affect in the future on everyday life, change approaches to it.

Fundamental research throughout the history of science is updating the epistemological resource. At the same time, the mechanisms and methodology of research are constantly changing, technical and technological tools are being modernized. Recognition of modem science as a complex, expanding process has led to a striking variety in the efforts to understand that process [3]. The modern realities of living in global markets are 
transforming the science itself, which in most cases solves applied problems, and creates the basis for applied research.

Increasingly, the results of scientific research are considered commercially, and this leads to the loss of moral and humanitarian component of science as such. On the one hand, discoveries in the industry of applied medicine, genetics, nanotechnology, artificial intelligence are necessary and in demand. On the other hand, such categories as "spirituality", "morality" and "good" in their philosophical, transcendental sense of the word are practically leveled.

Philosophy as a universal meaning-forming system, the highest scientific and theoretical form of cognition of the world, which goes beyond fundamental and applied knowledge, is able to metaphysically explain the deep nature of thinking, creativity, scientific search, discovery, invention. It was philosophy that defined the importance of the role of fundamental knowledge in the life of mankind.

There is, of course, a contradiction between empirical and metaphysical approaches. In one form or another problems of metaphysical skepticism and inductive skepticism have been central to theories of knowledge and philosophies of science throughout the history of philosophy, and the same remains true of philosophy of science today. The two problems are alike in calling into question our ability to have scientific knowledge by considering circumstances in which alternative hypotheses are consistent with the evidence we might have.

The problems differ in detail. Inductive skepticism trades on the fact that we are finite beings who only have a finite amount of data available at any time. Metaphysical skepticism trades on the assumption of a separation between the kinds of things we have evidence about and the kinds of things we wish to know about; even if we had infinite knowledge of things of the first kind, it would not suffice to determine the truth about things of the second kind. These problems are at the bottom of many disputes over the nature of scientific claims, the structure of scientific theories, and the appropriateness of belief in the claims of modern science [4]. However, the reality that we are studying is becoming less obvious, it can be constantly changed, updated.

The concepts of "image," "idea", "discovery", "innovation" are considered by philosophical science in a certain sequence. They point to how modern science was formed. Human continuously generates new ideas, but not all ideas can rise to the level of fundamental knowledge. Only that researcher is able to gain new knowledge who receives a lifelong education [5]. Thus, fundamental research expands the horizons of consciousness and project knowledge into the complex world.

Fundamental research is aimed at strengthening the intellectual potential of modern society, developing new mechanisms that contribute to the modernization of education - its primary, secondary, higher levels. Innovation in education provides an opportunity to create new professions and new jobs by learning new knowledge and introducing new technologies, creating continuity of the educational process [6]. Applied research is the result of the modernization of science itself, the development of its potential; it is directly involved in the development of innovation and the provision of innovation as the basis of the socio-economic development of modern Civilization.

Knowledge derived from applied research is focused on its direct use in narrow areas of professional activity (cybernetics, genetics, space, economics, and social management).

New knowledge becomes the main capital in modern society; it is not opening available to the general consumer, but, on the contrary, is encoded in various ways. They are eventually transformed into new technologies and thus generate competition between countries, corporations and enterprises. Technology is born out of a symbiosis of fundamental and applied knowledge. Technology is the result of a high degree of innovation in applied knowledge. 
Fundamental research is almost inseparable today from applied research, although their socio-cultural codes, as well as the ways in which knowledge is organized and broadcast are different. Fundamental research universalizes knowledge, and applied research segments it (see Figure 2 below).

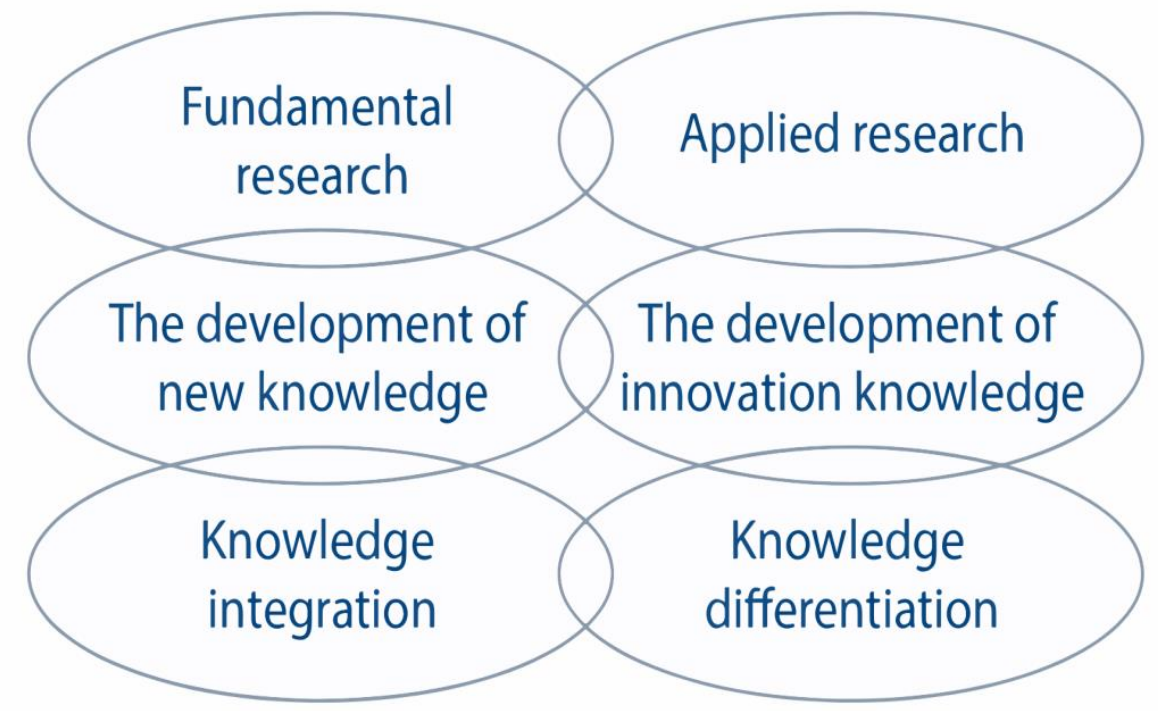

Fig. 2. The correlation of fundamental and applied knowledge

Result:

1) Fundamental sciences encompass natural, humanitarian, social and applied knowledge.

2) The formation of fundamental knowledge is a consequence of the emergence of philosophical methods of understanding reality.

Fundamental knowledge is a fairly broad concept; it draws a line between knowledge and ignorance, knowable and unknowable, possible and impossible, obvious and probable.

Fundamental knowledge is often presented as "accurate" knowledge. Mathematics, astronomy, biology, physics, chemistry and other "accurate" sciences study the various properties of nature and its laws. For example, nanotechnology includes such fundamental disciplines as quantum physics, molecular biology, computer science, chemistry. That is, there is a convergence of knowledge [7]. Consequently, the process of development of science is represented in all its dialectical complexity and diversity.

Thus, the scientific pictures of the world, modeled in the process of the generalization of the results of fundamental research, in the innovative space can change more often than in the historical space. In addition, today there is not one dominant scientific picture of the world, but many of such scientific pictures.

If we summarize the results of this study, we will get the following features (see Figure $3,4,5,6,7$ below):

Features of application of fundamental knowledge and their influence on innovative space as ontological phenomenon. 


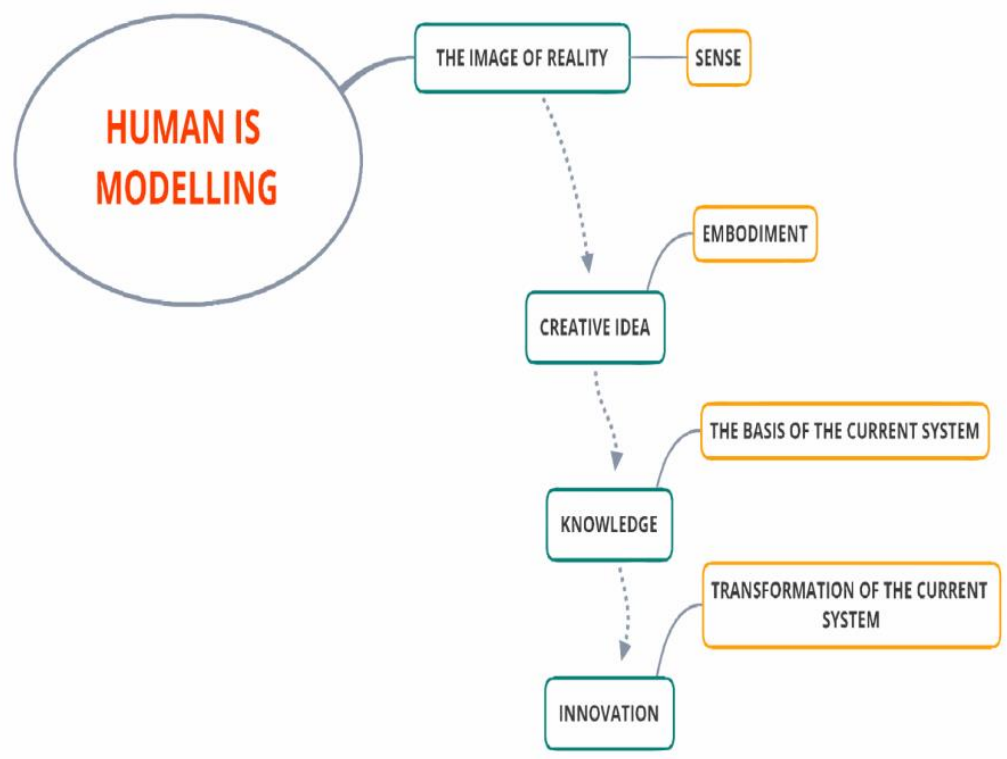

Fig. 3. Feature 1: Human consciousness, intelligence and fantasy as the main attributes of fundamental knowledge

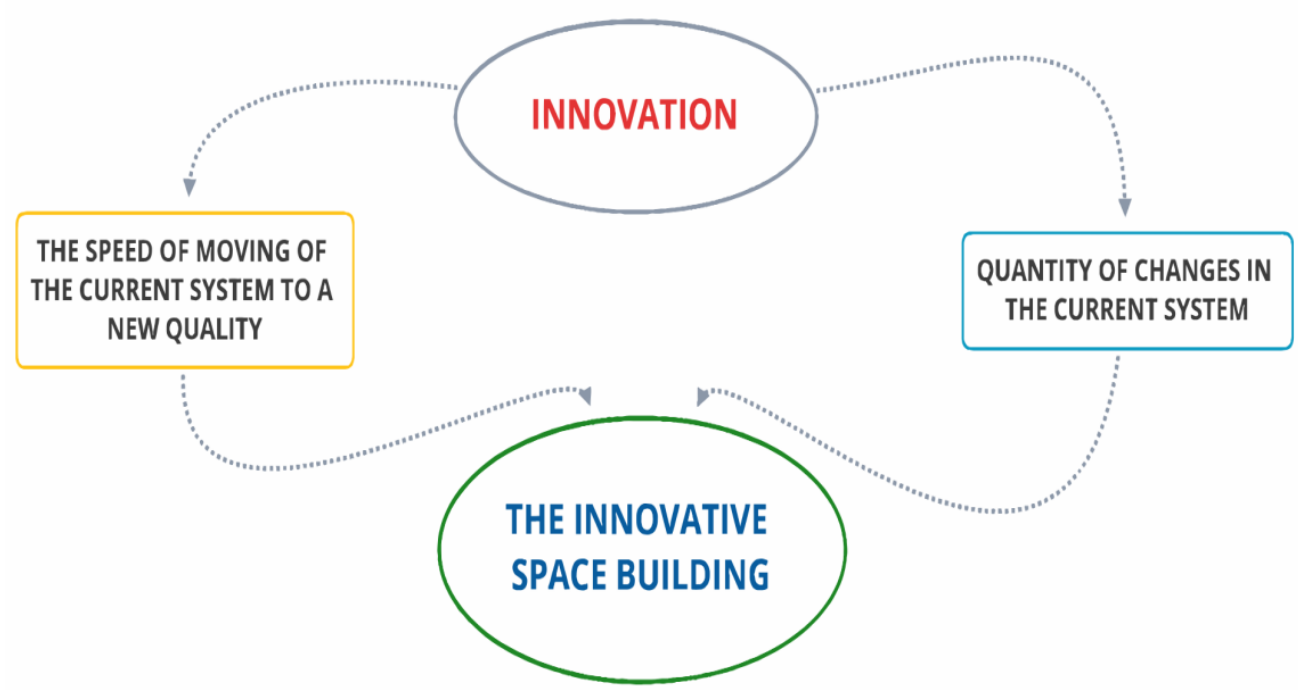

Fig. 4. Feature 2: Quantitative and qualitative changes as a result of human creativity 


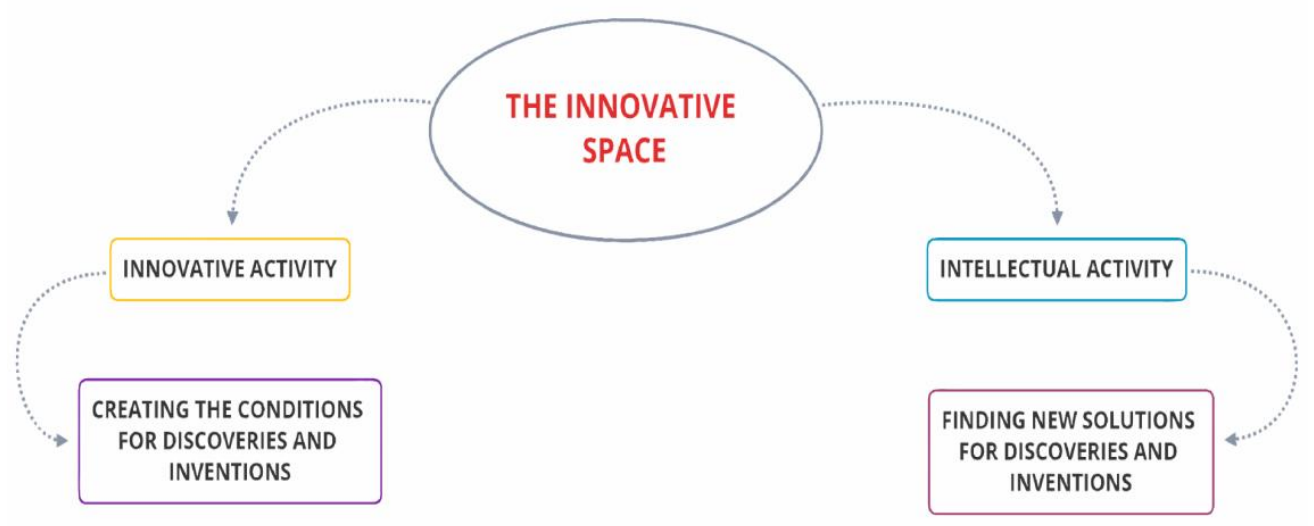

Fig. 5. Feature 3: The attraction to the "new" as a natural stimulus of the human

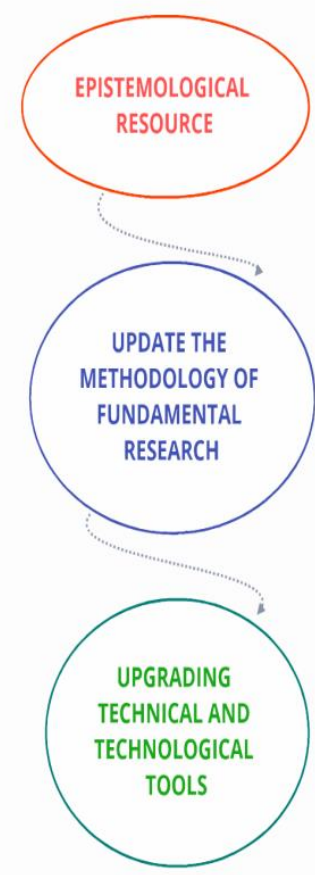

Fig. 6. Feature 4: Cognition as the driving force behind fundamental research 


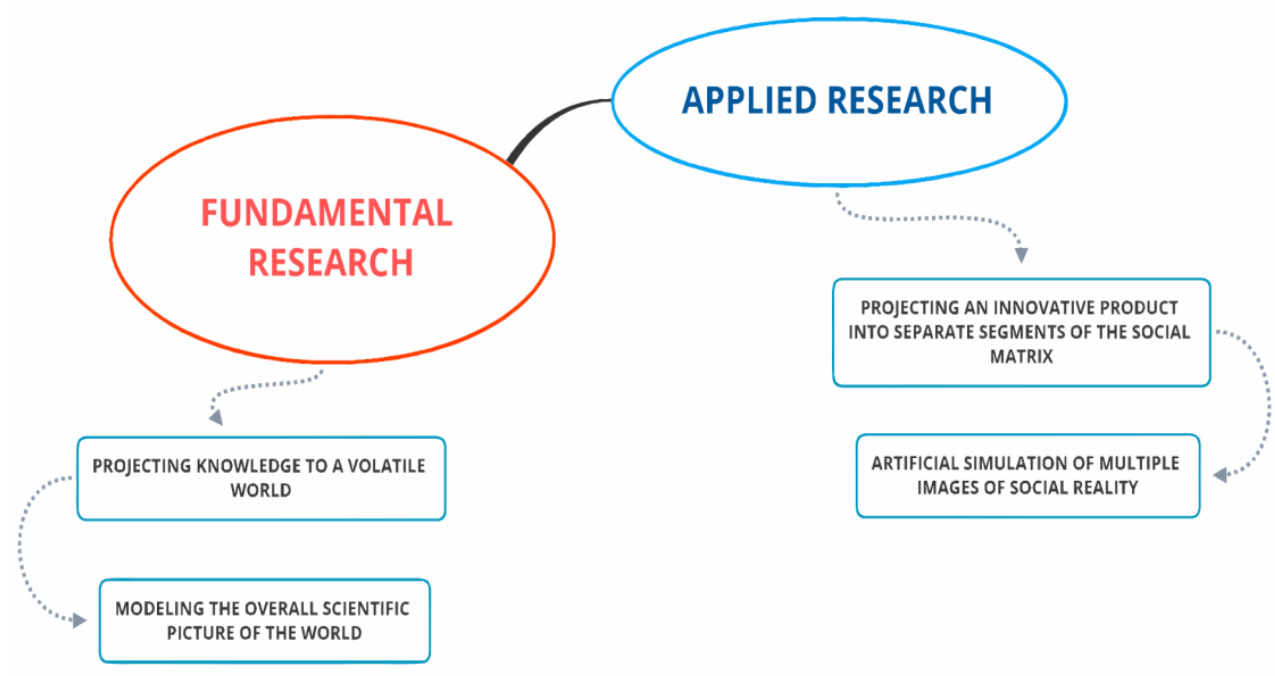

Fig.7. Feature 5: Innovative space as an artificial environment for correcting social and natural phenomena

Result: All of these features are connected with the development of philosophical epistemes, directing society to see the future perspective of civilization.

\section{Discussion}

The innovative process is the introduction of new intelligent solutions in various areas of life (architecture, fashion, design, transport or military industry), as well as the development and distribution of new technologies. Moreover, the development of technology requires special training and learning of new knowledge. It also requires a special organization of knowledge and training material.

L. Drotianko, S. Yahodzinskyi showed that in a globalized society, everybody faces with the need for processing and analyzing of large volume of data in the daily routine. Undoubtedly, the possibility of free and quick access to diverse information, the implementation of innovative technologies and machines, the development of printing and electronic libraries stimulates not only social processes, make them more dynamic, but also gives a chance to the wide audience to express the opinion, participate in discussing topical issues, to influence the decisions [8]. Technological innovations involve new or efficient production of existing product and machinery, new or improved technical processes. Thus, the innovation process requires: investment, new developments, new solutions, and qualitative improvement of the modernized area.

Fundamental knowledge can influence the innovative process in two ways. On the one hand, the changes are radical, and on the other hand, they are incremental. Periods of innovation stagnation can be reduced on the basis that the world has become global and the demand for improved quality of life is colossal.

A. Gudmanian, L. Drotianko, S. Sydorenko, O. Zhuravliova, S. Yahodzinskyi underline that globalization processes are currently penetrating all spheres of social life worldwide, above all, through steady and inevitable advance of information and communication technology [9]. The innovative process concentrates the creative power of new knowledge. The result of innovation is high economic efficiency in the production or consumption of 
the product, the intensification of new developments and inventions in the technical industries. In this case, a product with qualitatively new properties is created.

The innovative approach is effectively transported from the technical industry to the field of intelligent design as well as intelligent engineering. Consequently, the concept of "innovation" has a broad context. And the innovative space covers, practical, spiritual, intellectual, creative plane of social life.

O. Sidorkina, O. Skyba, N. Sukhova and T. Poda confirm that modern technology and consumer attitude towards nature, which at one time aimed at the happiness of people, has become a threat to the existence of humanity as such [10]. The innovative space creates the most acceptable conditions for the researchers and their inventions. Thus, talks about innovative production of knowledge [11].

T. Pinch

In this case, a new concept, device, or other things that facilitate activities may be the invention, and innovation is not associated with that situation when the innovation organizer has benefited from any benefit and when it has a positive effect. P. Drucker rightly argues that we can never know in advance what idea will survive [12]. Innovation strains the global management system, implements new or significantly improved marketing methods, uses new approaches in presentation of services, their presentation and promotion to markets, formation new marketing and management strategies [13]. Scientific creativity and a penchant for collaboration are variables, and they vary over time [14].

\section{Conclusion}

The "human-knowledge" interaction is a model of a new type of society called "The Society of Knowledge". In this society, the mind is a key instrument of human in the process of learning and developing the world. Knowledge is a product of smart and creative activity of human, the highest value, which human owns as a historical being, as well as the quintessence of human life. Social space is formed as a result of expansion and use of knowledge.

"Social space" means to share and unite all individuals. Social space is also a collection of certain goals, rights and responsibilities that affect the nature and quality of social relations. Social reality integrates individuals into the community in the process of their common livelihoods.

Social space as a virtuum is modeling specific conditions in which individuals construct their relationships, search for their place in society, and also produce vital meanings. Social virtuum also produces numerous social phenomena and processes, regulates them in space and time. It is manifested in the process of correlation of human actions and deeds.

According to its content social virtuum is a reflection of organization and life of society as a subject of historical process. It is a comprehensive, fluctuating formation that accumulates knowledge, experience, traditions, cultural codes, and also determines the level of development of the society and its key elements. Social virtuum expresses the nature of the use of fundamental knowledge and intellectual capacity of society to develop universal criteria for optimal future development of the entire social organism.

Human as an intellectual person, on the one hand, is a social being. It has the mind and consciousness and also is a subject of history, culture, civilization. It learns and constructs the world around, changes its architectonics, innovates it, deepens culture and models its own individual history. The essence of human, its origin and purpose, place in nature and society are the main problems of philosophy, science, religion and art. On the other hand, human is a spiritual, mysterious, creative; it is a cosmic scale substance that aims to obtain absolute knowledge.

Modern fundamental knowledge is a result of collective cognitive activity. Such kind of knowledge is represented not only as based on logic or facts, and that provides for 
empirical or practical verification of valuable data, but also as a set of all human irrational intensions. This means that any variation of reflection of reality in human thinking is valuable.

Modern science and methodology of science are aimed at gaining fundamental knowledge about the structure of the substance, new laws of nature, as well as understanding the inner mental dimension of spiritual reality. To a greater extent knowledge is the spiritual component of the internal microcosm. Knowledge of an individual (or group of individuals) is information. Information is a complex occurrence, abstraction containing an infinite number of variables. Possessing information, a person can solve any practical problem. Knowledge is an ambivalent to faith.

In philosophy, in the broadest sense of the word, knowledge is an image of reality in the mind of the subject, which is recorded in the form of concepts and representations (see Figure 8 below).

\section{Philosophical Sciences}

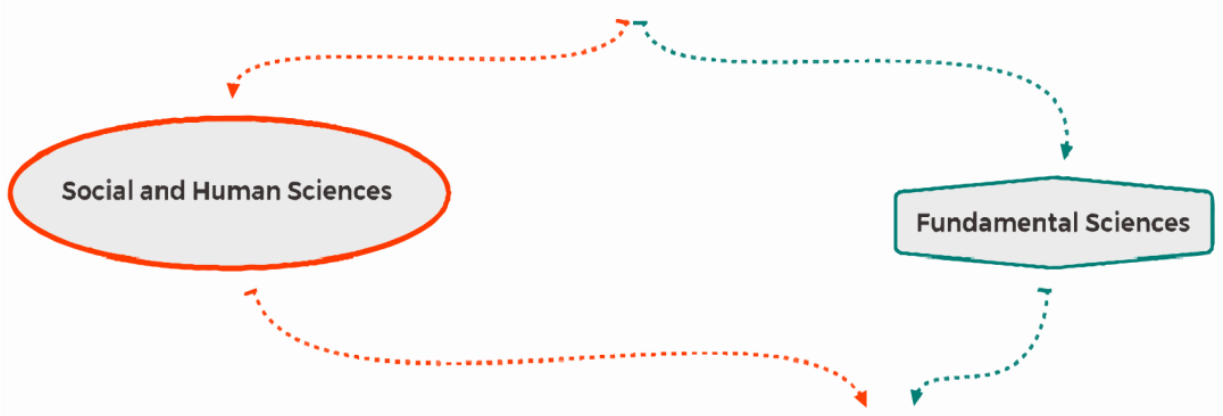

Applied Sciences

Fig.8. The process of displacing the philosophical sciences of man and society in the conditions of the dominance of applied knowledge

Result:

1) Philosophical sciences do not create a commercial market as a service sector, but form the worldview of human and society, create the prerequisites for future innovations in all areas of scientific knowledge.

2) Innovation is considered as an ideal image, a category of philosophy in all its senses.

Typically, fundamental knowledge is objective, fixed, expressed in a language or any other iconic system in the form of signs. However, such kind of knowledge can also be recorded in sensual images; it is obtained by direct perception of reality.

Cognition is not limited to the field of science, and fundamental knowledge in one form or another exists also beyond science. Science, philosophy, mythology, politics, religion as a form of public consciousness correspond to specific forms of knowledge. They are also fundamental. They are forms of knowledge that have a conceptual, symbolic or artistic basis. All these forms are also intertwined in a social virtuum.

Fundamental knowledge was formed historically as different kinds of knowledge proto-scientific, scientific, unscientific, routine-practical, intuitive, religious.

Proto-scientific knowledge existed in the early stages of human history and represented primary information about nature and the visible cosmos. Casual knowledge is the mark in a complex unfamiliar world, a basis for modeling the future, a resource for its foresight, but 
it can usually be controversial. However, everyday knowledge influences the configuration of social matrices, and the viewpoint of each person is considered in the process of life.

Fundamental scientific knowledge is based on rationality and is characterized by objectiveness and universality; it forms and innovates social virtuum. Virtuum is the result of innovation of the whole social sphere and the use of objective knowledge in the field of cybernetics, mathematics, technology, and cosmonautics. The main task of fundamental scientific research is description, explanation and foresight of any process and phenomenon in the innovative sphere of virtuum as a symbiosis of reality and simulation, as well as knowledge management.

Knowledge management is a separate branch of innovative science. The human mind seeks to understand how innovative knowledge is produced. Innovative knowledge may be externalized, collected, accumulated, saved, predicted, used, disseminated, declarative, procedural, meta-knowledge, vague knowledge, empirical, theoretical, practical, spiritualpractical, theorized, pre-scientific, scientific, methodological, subjective, objective, social, paradigmal, trans-subjective.

Numerous of these models of knowledge are connected to each other and affect the image of reality, constantly making adjustments. Management of innovative knowledge interprets knowledge as a form of information that is filled with context based on experience that is continuous and incomplete.

Information is a set of all possible data about the world, the sum of all future alternatives. Data may be a subject for observation, but they are constantly replenished and reinterpreted. In this case, innovative knowledge is information that is analyzed, processed, transmitted, and removed and these processes are continuous. This approach corresponds to the model of knowledge as a pyramid of increasing usefulness. This model translates innovative knowledge into the plane of virtual reality, creating a virtual knowledge.

"Virtual reality" or "artificial reality" is the world created by technical means; it is transmitted to human through its feeling: sight, hearing, smell, touch. Virtual reality is the pure innovative sphere; it mimics various influences on human consciousness, as well as numerous reactions to impacts. By computer synthesis of properties and reactions of virtual reality for human consciousness a convincing complex of sensations of reality is created, and all this is reproduced in real time.

Virtual reality objects usually behave themselves similar to the behavior of objects of material reality. The user can influence these objects according to real physics laws. However, often for entertainment purposes users of virtual worlds are allowed more than possible in real life. In these possibilities the sense of innovation takes place.

If virtual reality is a computer world, a simulator, the "virtuum" is a real matrix of social being [15], which is built as a result of development and deepening innovative knowledge.

\section{References}

1. J. Schumpeter, The theory of economic development: an inquiry into profits, capital, credit, interest, and the business cycle (New Brunswick, New Jersey, Transaction Publishers, 1983)

2. M. Katz, H. Rosen, Microeconomics (Irwin, 1991)

3. R. Olby, G. Cantor, J.R. Christie, Companion to the history of modern science (London, New York, Routledge, 1990). Available at: https://ru.bok2.org/book/2481656/857db0

4. M. Salmon, J. Earman, C. Glymour, J. Lennox, et.al., Introduction to the philosophy of science. A Text by Members of the Department of the History and Philosophy of Science of the University of Pittsburgh (Cambridge, Prentice-Hall, Inc. Hackett 
Publishing Company Indianapolis, 1992) Available at: http://fitelson.org/confirmation/salmon_introduction_to_philosophy_of_science.pdf

5. M. Laal, Procedia - Social and Behavioral Sciences 83 (4), 980-84 (2013). Available at: https://doi.org/10.1016/j.sbspro.2013.06.182

6. M. Laal, A. Laal, A. Aliramaei, Procedia - Social and Behavioral Sciences 116, 405256 (2014) Available at: https://www.researchgate.net/publication/261144349_Continuing_Education_Lifelong _Learning

7. M. Mehta, Bulletin of Science, Technology and Society 22 (4), 269-73 (2002) Available at: https://doi.org/10.1177/027046760202200402

8. L. Drotianko, S. Yahodzinskyi. V. Vernadsky, E3S Web of Conferences 135, 3079 (2019). Available at: https://doi.org/10.1051/e3sconf/201913503079

9. A. Gudmanian, L. Drotianko, S. Sydorenko, O. Zhuravliova, S. Yahodzinskyi, E3S Web of Conferences 135, 03081 (2019). Available at: https://doi.org/10.1051/e3sconf/201913503081

10. O. Sidorkina, O. Skyba, N. Sukhova, T. Poda, E3S Web Conferences 135, 03074 (2019). Available at: https://doi.org/10.1051/e3sconf/201913503074

11. T. Pinch, American Journal of Sociology American 105 (5), 69-83 (2000). Available at: https://www.journals.uchicago.edu/toc/ajs/105/5?mobileUi=0\&

12. P. Drucker, The age of discontinuity. Guidelines to Our Changing Society (New York, Harper \& Row, 1969). Available at: file:///C:/Users/Angel/AppData/Local/Temp/Binder4-Peter-DruckerThe\%20Age\%20of\%20Discontinuity(1).pdf

13. B. Bozeman, A. Link, Science and public policies 42 (3), 369-76 (2015). Available at: https://doi.org/10.1093/scipol/scu058

14. M. Bickard, F. Murray, J. S. Gans, Management science 61 (7), 1473-95 (2015). Available at: https://doi.org/10.1287/mnsc.2014.2052

15. Y. Kharchenko, Visnyk Natsionalnoho aviatsiinoho universytetu 1 (29), 26-30 (2019) UDC 1:316:327 